\title{
Cushing's disease: current medical therapies and molecular insights guiding future therapies
}

\author{
Darryl Lau, MD, Caleb Rutledge, MD, and Manish K. Aghi, MD, PhD \\ Department of Neurological Surgery, University of California, San Francisco, California
}

\begin{abstract}
OBJECT Cushing's disease (CD) can lead to significant morbidity secondary to hormonal sequelae or mass effect from the pituitary tumor. A transsphenoidal approach to resection of the adrenocorticotropic hormone (ACTH)-secreting pituitary adenoma is the first-line treatment. However, in the setting in which patients are unable to undergo surgery, have acute hypercortisolism, or have recurrent disease, medical therapy can play an important role. The authors performed a systematic review to highlight the efficacy of medical treatment of $C D$ and discuss novel molecular insights that could guide the development of future medical treatments of $C D$.
\end{abstract}

METHODS A search on current medical therapies for $C D$ was performed. After individual medical therapeutic agents for $C D$ were identified, each agent underwent a formal systematic search. The phrase "(name of agent) and Cushing's" was used as a search term in PubMed for all years up to 2014. The abstract of each article was reviewed for studies that evaluated the efficacy of medical treatment of CD. Only studies that enrolled at least 20 patients were included in the review.

RESULTS A total of 11 articles on 6 individual agents were included in this review. Specific medical therapies were categorized based on the level of action: pituitary directed (cabergoline and pasireotide), adrenal/steroidogenesis directed (ketoconazole, metyrapone, and mitotane), and end-tissue directed/cortisol receptors (mifepristone). The studies identified consisted of a mix of retrospective reviews and small clinical trials. Only pasireotide and mifepristone have undergone Phase III clinical trials, from which they garnered FDA approval for the treatment of patients with CD. Overall, agents targeting ACTH secretion and steroidogenesis were found to be quite effective in reducing urine free cortisol (UFC) to levels near normal. A significant reduction in UFC was observed in $45 \%-100 \%$ of patients and a majority of patients gained clinical improvement. Similarly, inhibition at the end-tissue level led to clinical improvement in $87 \%$ of patients. However, side-effect rates associated with these drugs are high (up to $88 \%$ ). Ketoconazole has been shown to enhance tumor appearance on MRI to facilitate pituitary resection. Promising molecular targets have been identified, including epidermal growth factor receptor, retinoic acid receptors, and cyclin dependent kinases. These pathways have been linked to the regulation of pro-opiomelanocortin expression, ACTH secretion, and tumor growth.

CONCLUSIONS Despite encouraging Phase III clinical trials leading to FDA approval of 2 agents for treatment of patients with $C D$, no agent has yet produced results comparable to resection. As a result, the molecular insights gained into $C D$ pathogenesis will need to continue to be expanded until they can lead to the development of medical therapies for $\mathrm{CD}$ with a favorable side-effect profile and efficacy comparable to resection. Ideally these agents should also reduce tumor size, which could potentially permit their eventual discontinuation.

http://thejns.org/doi/abs/10.3171/2014.10.FOCUS14700

KEY WORDS cortisol; Cushing's disease; medical therapy; molecular therapeutics; pituitary tumors

$\mathrm{C}$ USHING's syndrome (CS) is classically described as the signs and symptoms associated with prolonged exposure to pathologically elevated cortisol levels. Physical manifestations of CS include weight gain (central obesity), upper shoulder fat pads ("buffalo hump"), a rounded face, purple striae, proximal weakness, and hirsutism. ${ }^{52}$ Elevated cortisol levels also lead to pathological metabolic and physiological changes such as hypertension, psychological disturbances, deep venous thrombosis, coronary artery disease, diabetes mellitus, osteoporosis,

ABBREVIATIONS ACTH = adrenocorticotropic hormone; $C D=$ Cushing's disease; $C D K=$ cyclin-dependent kinase; $C N C=$ Carney Complex; $C S=$ Cushing's syndrome; EGFR = epidermal growth factor receptor; $\mathrm{HbA1c}=$ glycated hemoglobin; $\mathrm{MAS}=\mathrm{McC}$ une Albright syndrome; $\mathrm{MEN}=$ multiple endocrine neoplasia; $\mathrm{PAP}=$ pituitary adenoma predisposition; POMC = pro-opiomelanocortin; UFC = urinary free cortisol.

SUBMITTED October 6, 2014. ACCEPTED October 29, 2014.

INCLUDE WHEN CITING DOI: 10.3171/2014.10.FOCUS14700.

DISCLOSURE The authors report no conflict of interest concerning the materials or methods used in this study or the findings specified in this paper. 
immune suppression, impotence in men, and infertility in women. ${ }^{52}$ Therefore, it is important to adequately and successfully treat the underlying cause of elevated cortisol to prevent long-term morbidity.

The most common cause of CS is the exogenous use of corticosteroids (iatrogenic), but the most common endogenous cause of CS is the presence of an adrenocorticotropic hormone (ACTH)-secreting pituitary adenoma, also known as Cushing's disease (CD). ${ }^{17}$ Cushing's disease represents the disease etiology in more than $70 \%$ of all patients with an organic cause of CS. ${ }^{17}$ The current first-line therapy in the treatment of CD is surgery via a transsphenoidal approach to pituitary tumor resection. The immediate cure rates associated with neurosurgical resection of ACTH-secreting pituitary adenomas are promising, ranging from $65 \%$ to $90 \% .{ }^{26}$ However, recurrence rates remain relatively high at $20 \%$ to $25 \%$ on long-term follow-up. ${ }^{43,50}$ The mainstay management of recurrent $\mathrm{CD}$ usually consists of reoperation for pituitary tumor resection when possible, stereotactic radiation therapy, and, uncommonly, bilateral adrenalectomy. ${ }^{2,10}$ However, not all patients are candidates for surgery, and there are drawbacks associated with each modality of treatment. Therefore, there is a clear need for supplemental medical therapies in the treatment of CD. ${ }^{24}$

Medical therapies are used not only in the setting of recurrent disease, but also preoperatively in the setting of hypercortisolemic or severely symptomatic patients..$^{52}$ Medical therapies for $\mathrm{CD}$ are classified according to their site of action: at the pituitary gland by inhibiting ACTH secretion (upstream), at the adrenal gland by inhibiting steroidogenesis (midstream), or at the target tissue by blocking the glucocorticoid receptor (downstream; Fig. 1). ${ }^{27}$ There is a lack of a consensus regarding the ideal medical treatment of $\mathrm{CD}$, and published studies on the topic include small cohort sizes. ${ }^{13}$ In this article, we review the clinical efficacy of various agents used to treat hypercortisolism in CD and highlight translational insights gained from the molecular biology associated with CD that could guide the development of therapies in the future.

\section{Methods}

First, a search of medical therapies for CD was performed; this was conducted by searching the terms "medical treatment and Cushing's disease" to identify all articles published in PubMed up to 2014. Based on this search, articles were reviewed for agents that were used as a treatment for $\mathrm{CD}$. The criterion used in the identification of which agent would undergo a systematic search was the presence of at least 1 study evaluating its utility for the treatment for $\mathrm{CD}$. After identifying individual treatment agents for $\mathrm{CD}$, each agent underwent a formal systematic search. The phrase "(name of agent) and Cushing's" was used as a search term in PubMed for all years up to 2014 to identify all articles that included this phrase in the title and/or abstract. The references of systematic reviews were also reviewed for additional sources. The abstracts of each article were reviewed for studies that evaluated the efficacy of the agent for the treatment of CD. Only studies of at least 20 patients were included in this review. The Preferred Reporting Items for Systematic reviews and Me-
ta-Analyses (PRISMA) guidelines for systematic reviews were followed. ${ }^{36}$

The number of articles found, screened, and included for each agent were as follows: cabergoline (60 found, 14 screened, and 2 included), pasireotide (90 found, 26 screened, and 3 included), ketoconazole (233 found, 47 screened, 2 included), metyrapone (420 found, 38 screened, 1 included), mitotane (200 found, 9 screened, and 2 included), and mifepristone (98 found, 18 screened, and 1 included). Therefore, a total of 11 articles on 6 individual therapies for $\mathrm{CD}$ were included in the final review.

\section{Results}

\section{Current Medical Therapies for CD}

Pituitary-Directed Therapy: Inhibition of ACTH Synthesis and Secretion

Cabergoline. Cabergoline is a potent, long-acting dopamine 2 (D2) receptor agonist, frequently used in the treatment of prolactinomas (Fig. 1). ${ }^{37}$ Identification of dopamine (D2) receptors in corticotroph tumors led to clinical trials of cabergoline in patients with CD (Table 1). In a retrospective study of 30 patients with $\mathrm{CD}$, Godbout et al. reported normalization of urinary free cortisol (UFC) in 11 patients (36.6\%) with a median follow-up of 37 months. ${ }^{25}$ Patients were initiated at a dosage of 0.5 to 1.0 $\mathrm{mg} /$ week that was titrated up to $6.0 \mathrm{mg}$ /week. Similarly, in a prospective trial of 20 patients with CD treated with comparable doses of cabergoline, Pivonello et al. reported normalization of UFC in $50 \%$ of patients. ${ }^{45}$ No major adverse events were reported. These studies suggest that cabergoline is a safe treatment for patients with $\mathrm{CD}$ who fail first-line treatment, albeit with efficacy rates less than other agents used to treat $\mathrm{CD}$.

Pasireotide. A large proportion of pituitary tumors in CD express multiple somatostatin receptor subtypes, and in vitro studies have shown that activation of these somatostatin receptors, specifically SST5, leads to inhibition of ACTH secretion. ${ }^{8,28}$ Targeting of these receptors with somatostatin analogs such as octreotide has been ineffective for the treatment of CD. ${ }^{4}$ Pasireotide is a unique somatostatin analog because this agent is able to interact with 4 of 5 subtypes of somatostatin receptors and has particularly high affinity for the SST5 receptor (i.e., 40-fold higher than other agents; Fig. 1). ${ }^{14,48}$ Therefore, its clinical efficacy for the treatment of CD should be relatively greater than other somatostatin analogs, which are more selective in their receptor interactions. A total of 3 studies have investigated pasireotide efficacies for CD between 2009 and 2014 (Table 1). Boscaro et al. performed a Phase II, multicenter, single-arm study to test the safety and efficacy of pasireotide for the treatment of CD. ${ }^{12}$ In a total of 39 patients, 15 days of pasireotide treatment led to a reduction of UFC in $76 \%$ of patients; a mean UFC reduction of $45 \%$ was observed (1231 to $683 \mathrm{nmol} / 24 \mathrm{hrs}$ ) and $17 \%$ of patients had complete responses (normalization of UFC). However, $87 \%$ of the patients experienced at least 1 drugrelated adverse event (mostly minor side effects). Given its promising results, Colao et al. tested pasireotide in a landmark Phase III, double-blind, randomized trial of 162 patients with CD. ${ }^{18}$ Patients received either low-dose or 


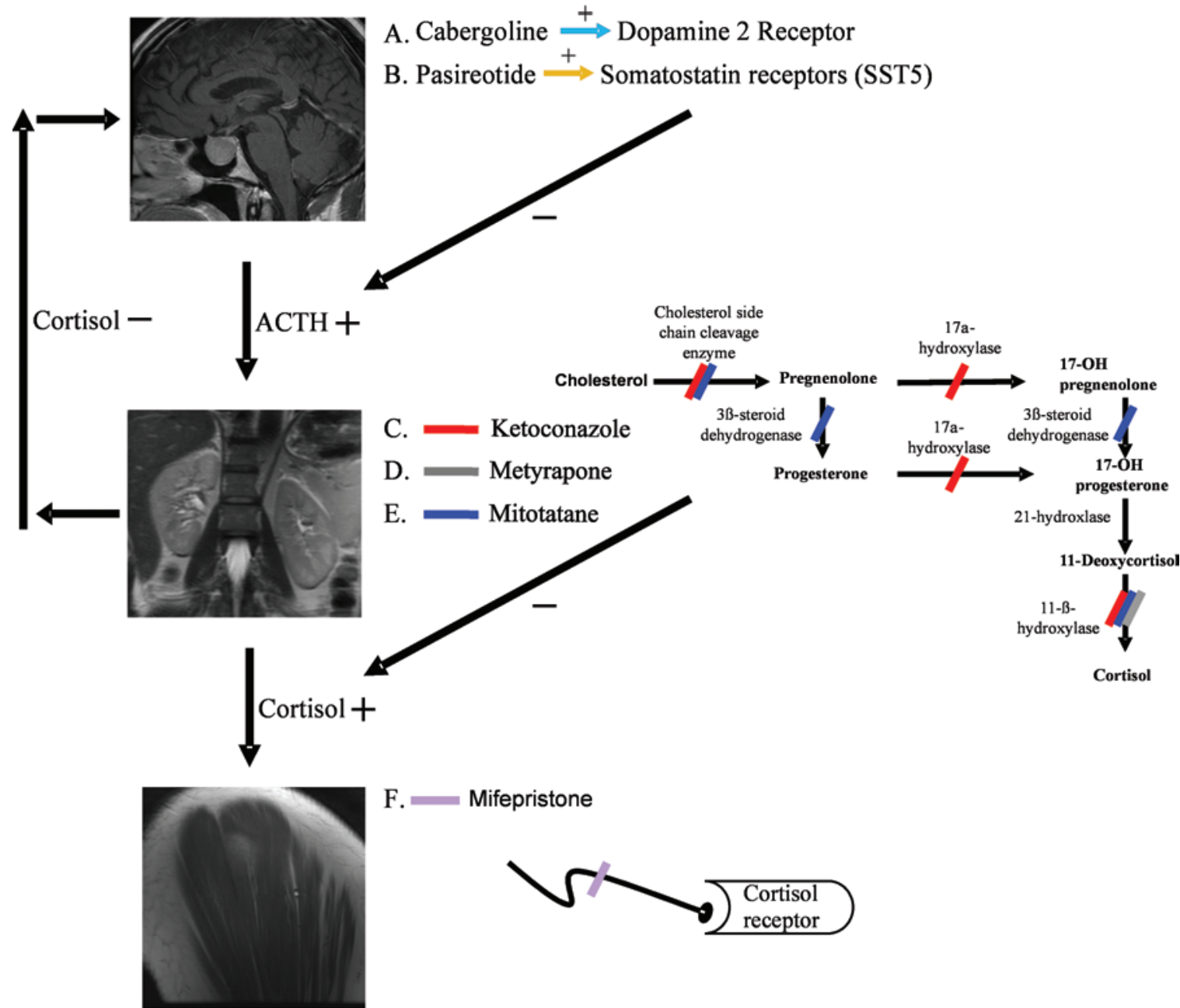

FIG. 1. Site of actions and mechanisms of current medical therapies for CD. Cabergoline (A) is a potent long-acting dopamine-2 receptor agonist that causes the inhibition of $\mathrm{ACTH}$ secretion. Pasireotide $(\mathrm{B})$ is a unique somatostatin analog that has particularly high affinity for the SST5 receptor that causes inhibition of ACTH secretion. Ketoconazole $(C)$ is a widely used antifungal agent that inhibits cytochrome P450 enzymes involved with steroidogenesis, including 17,20-lysase, 11 $\beta$-hydroxylase, and 17 $\alpha$-hydroxylase and side-chain cleavage. This results in decreased cortisol synthesis and secretion. Metyrapone (D) is a synthetic agent that inhibits $11 \beta$-hydroxylase activity and prevents the conversion of 11-deoxycortisol to cortisol. Mitotane $(E)$ is an antineoplastic agent that disrupts steroidogenesis through inhibition of side-chain cleavage, $3 \beta$ steroid dehydrogenase, and $11 \beta$-hydroxylase. Mifepristone $(F)$ is a receptor antagonist against glucocorticoid receptors that blocks cortisol receptor interaction. + = activation, = inhibition. The sagittal MR image of a brain (upper) shows a pituitary mass in a patient with CD. The coronal MR image (middle) is of the adrenal glands. The sagittal MR image (bottom) is of a deltoid muscle (target organ).

high-dose pasireotide treatment. The study demonstrated that pasireotide led to a median UFC decrease of at least $50 \%$ at just 2 months into treatment. Complete responses occurred in $13 \%$ of patients who received low-dose treatment and $25 \%$ in patients who received high-dose treatment. Patients who had excessively high UFC (5 times the upper limit of normal) prior to initiation of treatment had lower odds of achieving normal UFC, suggesting that medical treatment may be most appropriate for patients with moderately elevated UFC. Similar to the study by Boscaro et al., ${ }^{12}$ the incidence of treatment-related adverse events was high; specifically, $73 \%$ of patients had hyperglycemia events. The patients from the same trial were then assessed by Pivonello et al. for clinical response and symptomatic relief associated with reduction in UFC at
12 months of follow-up. ${ }^{46}$ It was shown that the reduction in UFC resulted in significant improvements in signs and symptoms of $\mathrm{CD}$ at 12 months. Following treatment with pasireotide, patients had a significant reduction in blood pressure and low-density lipoprotein levels; in addition, patients had lower body mass indices, weight, and waist circumferences. On the basis of these results, the FDA granted pasireotide approval for the treatment of CD in December 2012, although the statement of FDA approval acknowledged that surgery remained the front-line treatment and the drug would be of particular utility in patients not eligible for surgery or patients with recurrence..$^{40}$

Adrenal Target Therapy: Inhibitor of Steroidogenesis.

Ketoconazole. Ketoconazole, a widely used antifungal 


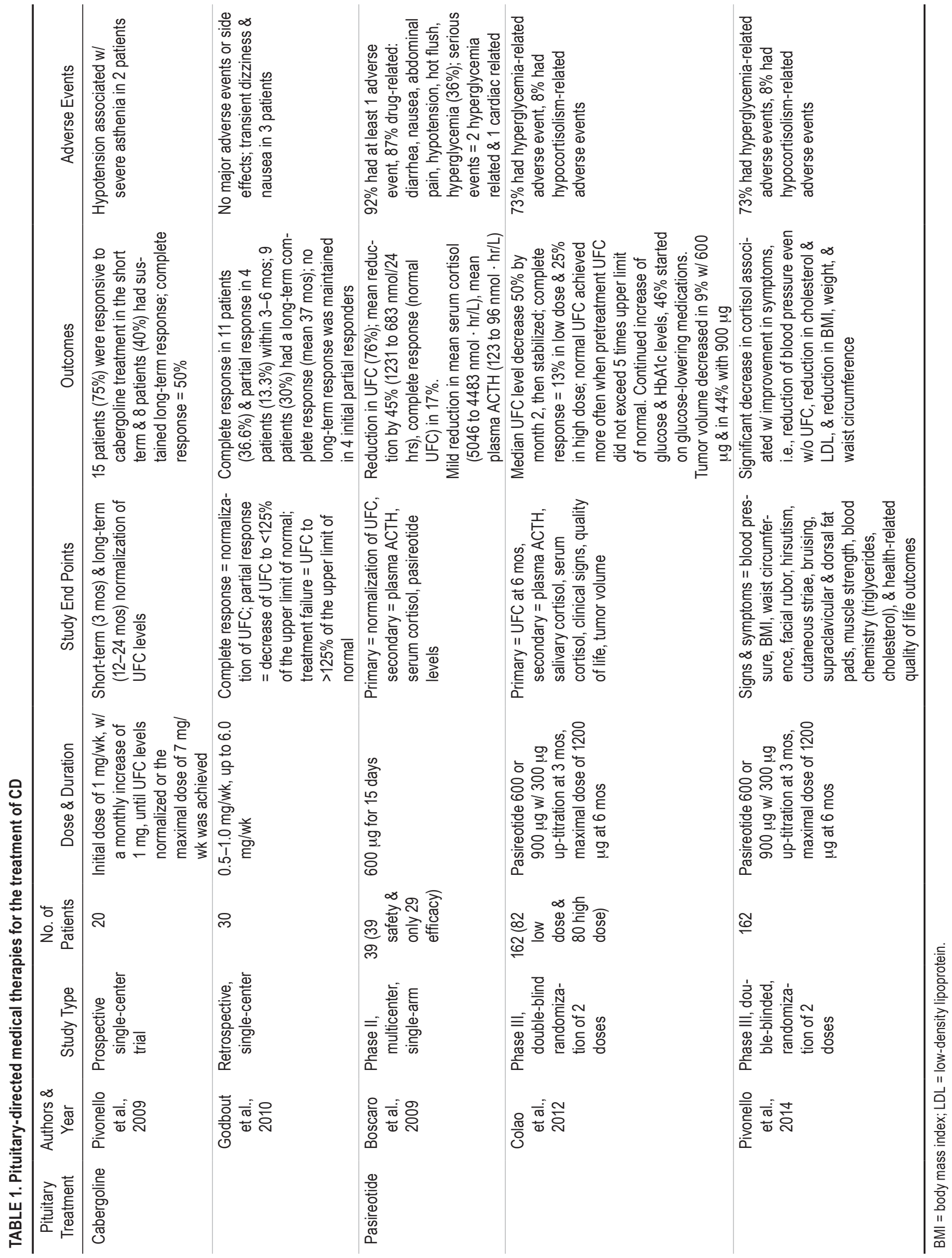


agent, is an imidazole derivative that inhibits cytochrome P450 enzymes involved with steroidogenesis, including 17,20-lysase, 11 $\beta$-hydroxylase, and 17 $\alpha$-hydroxylase and side-chain cleavage (Fig. 1) ${ }^{34}$ It is one of the oldest medical treatments for CD, with studies from the 1980s establishing efficacy of the agent for CD. ${ }^{5}$ In addition, there is a growing literature base that shows ketoconazole may benefit $\mathrm{CD}$ by extra-adrenal actions through antagonist activity against glucocorticoid receptors at high concentrations via direct binding. ${ }^{34,42}$ The 2 studies of ketoconazole in CD treatment that met the inclusion criteria for this review were small retrospective reviews. Moncet et al. and Castinetti et al. both reviewed their experience of utilizing ketoconazole for the treatment of CD in 54 and 38 patients, respectively (Table 2). ${ }^{16,38}$ The outcomes of the Moncet et al. study were promising, with $85 \%$ of patients obtaining either normal or subnormal UFC; 38 in addition, all patients improved clinically. Castinetti et al. demonstrated less successful outcomes with only $45 \%$ of patients achieving normalized UFC; only patients with measurable reductions in UFC demonstrated improvements in signs and symptoms of $\mathrm{CD} .{ }^{16}$ The most common adverse events associated with ketoconazole use were hepatotoxicity, adrenal insufficiency, and gastrointestinal distress. These side effects are reported to occur in at least $15 \%$ of patients and have limited the utility of ketoconazole to date..$^{20}$ Interestingly, in the same study by Castinetti et al., ketoconazole allowed identification of a pituitary adenoma in $33 \%$ of patients who had adenomas that were not visible on MRI prior to treatment. ${ }^{16}$ This unique property of ketoconazole may have significant implications in the surgical management of patients with MRI-negative CD; administration of ketoconazole may facilitate the identification of adenomas that were initially MRI-negative and guide future resection.

Metyrapone. One of the main steroidogenesis enzymes is $11 \beta$-hydroxylase, and its role is to facilitate the conversion of 11-deoxycortisol to cortisol. Therefore, inhibition of this rate-limiting enzyme effectively prevents cortisol synthesis and availability. Metyrapone is a synthetic agent that inhibits $11 \beta$-hydroxylase activity and was originally developed for the diagnosis of adrenal insufficiency (Fig. 1). ${ }^{6}$ In patients with an intact hypothalamic-pituitaryadrenal axis, inhibition of $11 \beta$-hydroxylase leads to decreased cortisol, increased ACTH, and an accumulation of 11-deoxycortisol (cortisol precursor). There is only 1 study evaluating the efficacy of metyrapone in CD (Table 2). Verhelst et al. performed a retrospective, single-center review on the use of metyrapone for the treatment of CS (Table 2) ${ }^{54}$ Among the 91 patients with CS reviewed, 57 patients had CD. These authors demonstrated that within 2 hours of administration of metyrapone all patients showed a decrease in serum cortisol and expected increases in 11-deoxycortisol and ACTH. The most common adverse event was transient hypoadrenalism. Unfortunately due to the nature of the study, the data and outcomes provided did not indicate whether metyrapone was beneficial on a long-term basis for CD. Further studies will be needed to determine whether metyrapone is able to maintain its durability and improve clinical signs and symptoms associated with $\mathrm{CD}$.
Mitotane. Mitotane is an antineoplastic medication approved for the treatment of metastatic adrenal carcinoma by causing controlled destruction of adrenal tissue via apoptosis. ${ }^{32}$ This agent also alters steroid metabolism and directly suppresses the adrenal cortex, leading to hypocortisolism (Fig. 1). ${ }^{32}$ Mitotane, in conjunction with irradiation, was first used in patients with CD in the 1970s and was able to provide remission for some patients. ${ }^{55}$ In a subsequent prospective trial of 36 patients, Schteingart et al. reported clinical and biochemical remission in 29 (81\%) of 36 patients with $C D$ treated with a mean daily dose of $4.0 \mathrm{~g}$ /day (Table 2). ${ }^{49}$ Plasma mitotane concentrations greater than $8.5 \mathrm{mg} / \mathrm{L}$ were associated with normal UFC at all time points. More recently, Baudry et al. reported remission in $72 \%$ of patients when treated with long-term mitotane at a mean dose of $2.6 \mathrm{~g} /$ day. ${ }^{9}$ Median follow-up was 97 months. However, after treatment discontinuation a majority of patients experienced a recurrence of hypercortisolism; only $29 \%$ did not experience a recurrence. Similar to the study of Schteingart et al., Baudry et al. also found that hormonal control was closely associated with mitotane plasma concentration. In both studies there was a high rate of treatment intolerance and withdrawal.

\section{Tissue-Directed Therapy: Inhibition of Cortisol Receptors.}

Mifepristone. Mifepristone is a progesterone receptor antagonist with glucocorticoid receptor antagonist activity at high concentrations (Fig. 1). Mifepristone has a 3 times greater binding affinity for glucocorticoid receptors than dexamethasone. ${ }^{15}$ In the Study of the Efficacy and Safety of Mifepristone in the Treatment of Endogenous Cushing's Syndrome (SEISMIC) - a 24-week multicenter, Phase III open-label trial after failed multimodality therapy at 14 US medical centers-a majority of patients experienced improvements in metabolic/hormonal and clinical status (Table 3). ${ }^{22}$ Fifty patients with CS (43 with CD) and impaired glucose intolerance or hypertension were treated with 300-1200 mg daily of mifepristone. Of the 50 patients, $87 \%$ experienced a significant improvement in clinical signs and symptoms. Mean glycated hemoglobin (HbA1c) decreased from $7.4 \%$ to $6.3 \%$ and fasting plasma glucose decreased from $149 \mathrm{mg} / \mathrm{dl}$ to $105 \mathrm{mg} / \mathrm{dl}$. An improvement in diastolic blood pressure was noted in $38 \%$ of patients. A weight change of more than $5 \%$ was observed and there was a significant decrease in waist circumference (women $-6.8 \mathrm{~cm}$ and men $-8.4 \mathrm{~cm}$ ). While $88 \%$ were reported to have an adverse event, most were minor and there were few serious adverse side effects. On the basis of this study, mifepristone was awarded FDA approval for treating hyperglycemia associated with $\mathrm{CD}$ because, while there were several benefits of mifepristone treatment of CD patients, hyperglycemia was the aspect of CD that responded best to mifespristone. ${ }^{21}$

\section{Molecular Biology and Future Targeted Therapy for CD}

The majority of $\mathrm{CD}$ cases are sporadic, but some do arise as a manifestation of particular familial syndromes. The syndromes most commonly associated with CD are McCune Albright Syndrome (MAS), multiple endocrine neoplasia (MEN) Type 1 (MEN1), Carney Complex (CNC), 


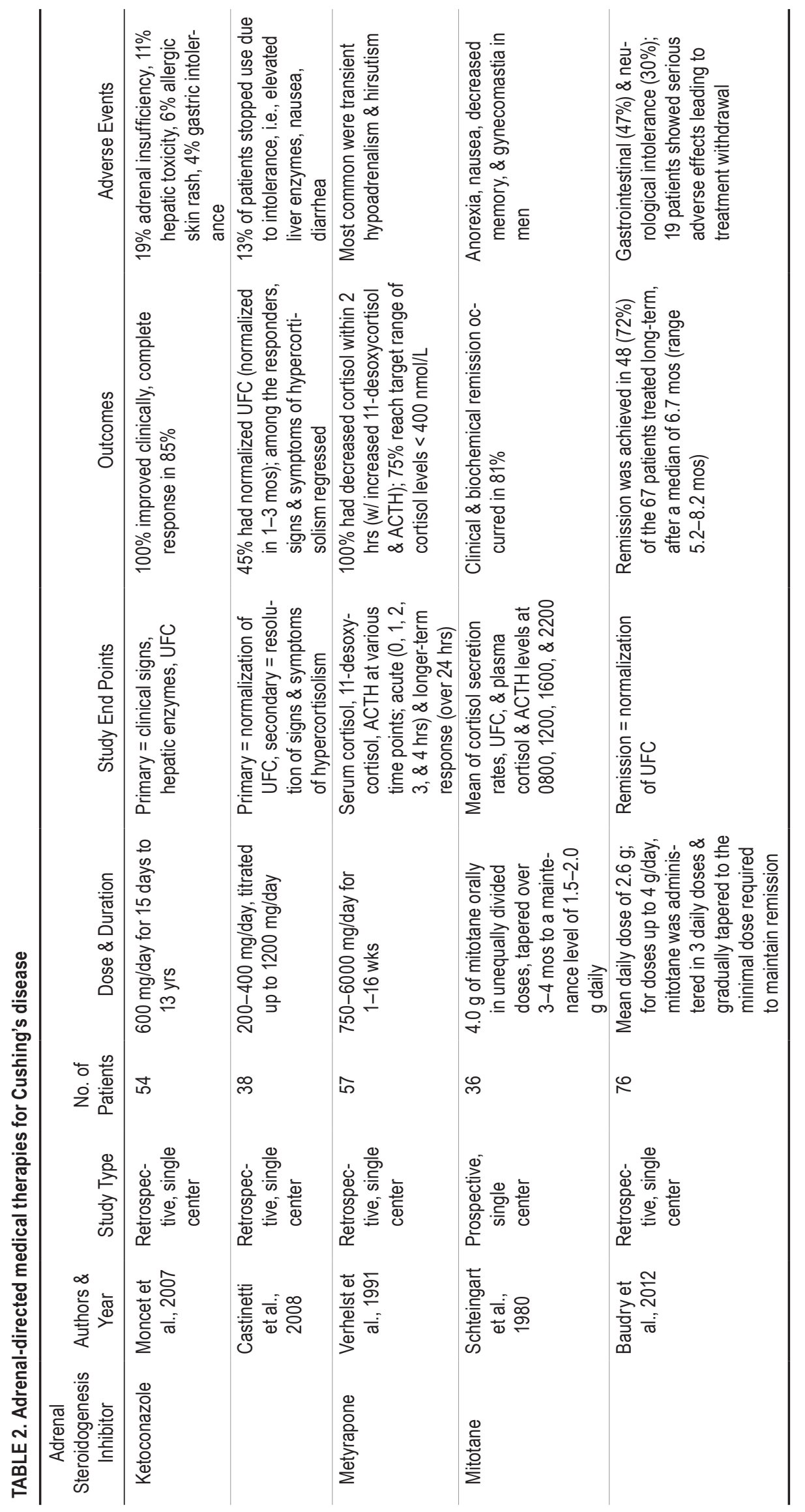


TABLE 3. End-organ directed therapy for CD

\begin{tabular}{|c|c|c|c|c|c|c|}
\hline $\begin{array}{l}\text { Authors } \\
\& \text { Year }\end{array}$ & Study Type & $\begin{array}{l}\text { No. of } \\
\text { Patients }\end{array}$ & $\begin{array}{l}\text { Drug, Dose, \& } \\
\text { Duration }\end{array}$ & Study End Points & Outcomes & Adverse Events \\
\hline $\begin{array}{c}\text { Fleseriu } \\
\text { et al., } \\
2012\end{array}$ & $\begin{array}{l}\text { Prospective, } \\
\text { open-label, } \\
\text { multicenter } \\
\text { study }\end{array}$ & $\begin{array}{l}50 \text { CS, } \\
43 \text { CD }\end{array}$ & $\begin{array}{l}\text { Mifepristone } \\
\text { 300-1200 mg } \\
\text { once daily }\end{array}$ & $\begin{array}{l}\text { ACTH \& pituitary } \\
\text { MRI, clinical } \\
\text { signs \& symp- } \\
\text { toms }\end{array}$ & $\begin{array}{l}\text { 2-fold increase in ACTH in } 72 \% \text { of } \\
\text { patients treated for a median } \\
\text { duration of } 11.3 \text { mos; } 87 \% \text { im- } \\
\text { proved in clinical status (mean } \\
\text { HbA1c, fasting plasma glucose, } \\
\text { diastolic blood pressure, weight } \\
\text { change, \& waist circumference }\end{array}$ & $\begin{array}{l}88 \% \text { of patients, most commonly } \\
\text { nausea/vomiting, fatigue, } \\
\text { headache, decreased blood } \\
\text { potassium, arthralgia, edema, } \\
\text { hypertension, dizziness, de- } \\
\text { creased appetite, endometrial } \\
\text { thickening }\end{array}$ \\
\hline
\end{tabular}

MEN1-like phenotype (MEN4), and pituitary adenoma predisposition (PAP) syndromes..$^{11,19,30}$ Genetic aberrations for each of these syndromes have been identified: MAS (mutation in guanine nucleotide-binding protein), MEN1 (mutation in menin), CNC (mutation in a subunit of protein kinase A), MEN4 (mutation in cyclin-dependent kinase $[\mathrm{CDK}]$ inhibitor $1 \mathrm{~B})$, and PAP (mutation in aryl hydrocarbon receptor interacting protein) ${ }^{19}$

In the case of sporadic $\mathrm{CD}$, there remains a lack of a clear understanding underlying the initiating and propagating molecular events that lead to the development of ACTH-secreting pituitary adenomas. ${ }^{35}$ The abnormal cell signaling pathways frequently encountered in pituitary adenomas are also observed in the tumorigenesis of various other tumor types. Most notably, often there are alterations in the serine-threonine kinases involved in the Ras-RafMAPK cascades and the PI3K-AKT-mTOR pathways. ${ }^{1,29}$ Particularly for ACTH-secreting pituitary adenomas, epidermal growth factor receptor (EGFR) and its downstream activation of Ras-Raf-MAPK has been shown to be intricately involved in the secretion of pro-opiomelanocortin (POMC), the precursor to ACTH. ${ }^{22}$ POMC expression and ACTH secretion is enhanced when EGFR is activated. A laboratory study demonstrated that inhibition of the EGFR with gefitinib attenuated POMC expression, decreased ACTH secretion, inhibited tumor cell proliferation, and induced apoptosis in ACTH-secreting pituitary adenomas. ${ }^{22}$ Given the frequent use of EGFR inhibitors in cancer treatment, further study of them in treating CD may be warranted.

More recently, retinoic acid has been reported to suppress ACTH secretion in CD.7,31,44 The mechanism underlying this clinical observation remains unclear and there have been contradictory results in the literature. In 2001, it was shown that retinoic acid decreases POMC transcription and ACTH secretion through activation of orphan receptors Nur77 and Nurr1.41 In addition, retinoic acid inhibited cell proliferation, increased caspase-3 activity, and induced cell death in ACTH-secreting adenoma cells. In a separate laboratory study by Uruno et al., the role of the retinoic acid receptor was examined in greater detail. ${ }^{53}$ Surprisingly, the authors found that the retinoic acid receptor interacts closely with NeuroD1 and Tpit expression and resulted in increased POMC mRNA expression, ACTH secretion, and POMC promoter activity. These findings are contradictory to those in earlier studies. Additional molecular and preclinical translation studies of retinoic acid for the treatment of CD are needed to further clarify its role as a potential therapeutic agent.

Molecular and genetic comparisons of silent pituitary corticotroph adenomas and ACTH-secreting pituitary adenomas have revealed that ACTH-secreting adenomas harbor upregulation of key cell cycle regulators, specifically CDK N2A. ${ }^{51}$ Zebrafish and murine models of pituitary corticotroph tumors have expanded the knowledge of CDK's role in ACTH-secreting pituitary adenomas. The inhibition of CDK pharmacologically has been shown to result in the suppression of $\mathrm{ACTH}$ and corticosterone levels. ${ }^{33}$ In addition, there is evidence that certain CDKs such as roscovitine, a $\mathrm{CDK} 2 /$ cyclin $\mathrm{E}$ inhibitor, result in inhibition of tumor growth and tumor cell senescence. ${ }^{33}$ Further translational studies are needed to assess its clinical efficacy.

\section{Discussion}

Cushing's disease is the most common cause of CS and can lead to significant mental and physically morbidity. ${ }^{52}$ The first-line treatment of CD is resection of the ACTHsecreting pituitary adenoma with the goal of normalized cortisol levels. ${ }^{2}$ However, in patients who are not surgical candidates, develop recurrent disease, or have acute signs and symptoms of hypercortisolism, medical therapy may be the fundamental treatment modality. Currently, there are very few medical agents available for the treatment of CD. ${ }^{24}$ In general, agents targeting ACTH-secreting tumors and steroidogenesis have been reported to be quite effective in reducing UFC to normal levels. Significant reductions in UFC were observed in $45 \%$ to $100 \%$ of patients among available studies, and a majority of patients achieved clinical improvement. $912,16,18,25,38,45,46,49,54$ Similarly, blocking glucocorticoid receptors is effective in preventing the clinical signs and symptoms of CS. ${ }^{22}$ However, caution regarding these results need to be taken because there are very few studies available and many of the studies consisted of retrospective reviews with small patient cohorts.

Pasireotide and mifepristone are the only agents to have undergone Phase III clinical trials in the treatment of CD, and as a result of these trials became the only agents to have garnered FDA approval for the treatment of particular patients with CD. ${ }^{18}$ However, there are drawbacks associated with each agent. Pasireotide has an extremely high incidence $(87 \%)$ of side effects and mifepristone's approval was only for treating CD cases with severe hyper- 
glycemia. There is a clear need to identify novel medical therapies for $\mathrm{CD}$ with a favorable safety profile, broad efficacy for all manifestations of CD, and an efficacy more comparable to resection, the way dopamine agonists are for prolactinomas.

It will be important for future trials to not only monitor for hormonal responses but to also monitor pituitary tumor size response as well. CD is unique to other forms of CS because of the presence of a mass lesion within the small boundary of the sella. While most CD-causing pituitary adenomas are microadenomas with no threat of mass effect, the efficacy of surgery for microadenomas means that CD-causing macroadenomas are often overrepresented in patients undergoing medical treatment. If these tumors grow during medical treatment the way growth hormonesecreting tumors grow in patients with acromegaly while being treated with pegvisomant, they can result in mass effect, producing hypopituitarism, cranial nerve palsies, and visual field deficits. ${ }^{39}$ One approach to preventing and perhaps reducing tumor burden could be combining upstream inhibitors with mid- or downstream inhibitors. For example, a case report by Ahmed et al. described a patient that experienced complete resolution and disappearance of an ACTH-secreting macroadenoma after undergoing combined ketoconazole and cabergoline medical therapy for 4 months. ${ }^{3}$ Future studies of medical therapies should be cognizant of tumor burden because agents that eliminate tumor burden will likely be the only ones from which patients may eventually be weaned, which can occur in some patients with small prolactinomas treated using dopamine agonists.

There is evidence that medical therapies that act at the level of the adrenal gland to inhibit steroidogenesis may result in pituitary tumor growth. ${ }^{16}$ It is hypothesized that tumor growth is the result of a lack of negative feedback that leads to increased ACTH synthesis and tumor growth. ${ }^{2}$ While this tumor growth can create a risk for symptomatic mass effect, neurosurgeons may be able to use this phenomenon to their advantage. In the study by Castinnetti et al., there was a suggestion that treatment with ketoconazole led to visualization of pituitary adenomas that were not visible prior to treatment. ${ }^{16}$ After these pituitary adenomas were radiologically detectable, the patients underwent transsphenoidal resection of the tumor and were cured of their disease. Therefore, in patients with a negative dynamic pituitary MR image who have biochemical evidence of $\mathrm{CD}$, while surgical exploration guided by inferior petrosal sinus sampling may be an appropriate initial treatment, one advantage of using ketoconazole as a subsequent treatment is its potential to facilitate identification of the ACTH-secreting pituitary adenoma that could lead to resection for cure. ${ }^{47}$ Ketoconazole may be an option in the management of MRI-negative $\mathrm{CD}$. It is likely that this effect only occurs with inhibitors of steroid biogenesis such as ketoconazole, rather than upstream CD treatments such as pasireotide. The use of ketoconazole as an agent to facilitate identification of ACTH-secreting adenomas has not been directly studied and its efficacy stems only from observations in previous studies of CD. There continues to be a need for future studies to evaluate ketoconazole's utility for the identification of ACTH-secreting adenomas.
As our understanding of the pathogenesis and tumorigenesis of ACTH-secreting pituitary adenoma expands, there will be ongoing development of molecularly targeted therapies for $\mathrm{CD}$. There is already a growing body of literature on targeting EGFR, retinoic acid receptors, and CDK with specific inhibitors for CD. ${ }^{23,31,44}$ Future studies evaluating the clinical efficacy of targeting these and other pathways are needed for the treatment of $C D$.

There are a few limitations to this review. The medical management of $\mathrm{CD}$ has been described for decades and multiple agents have been used in the treatment of CD. However, most articles involve small cohorts and case reports. Therefore, the systematic search performed in this review and the use of the study size criterion of at least 20 patients resulted in the exclusion of several agents that have been used in the medical management of $\mathrm{CD}$, such as temozolomide. Current studies also suffer from lack of consistent outcome endpoints. Nonetheless, findings from available studies are still able to help guide the medical management of patients with $\mathrm{CD}$.

\section{Conclusions}

There remains a paucity of safe and effective medical therapies for $\mathrm{CD}$, and there is a need for additional clinical trials assessing their efficacies. According to the studies available, medical therapies targeting the pituitary (ACTH secretion), adrenal (steroidogenesis), and end tissue (cortisol receptors) are all relatively effective. In addition, there are examples of ketoconazole facilitating radiological identification of CD-causing adenomas on MRI to facilitate their resection. Unfortunately, these available therapies are associated with high rates of side effects and do not reduce tumor size. Recently there has been an accumulation of data and knowledge regarding the molecular biology and tumorigenesis of ACTH-secreting tumors in CD. With this new understanding, future development of medical therapies will hopefully include therapies that induce biochemical remission with minimal side effects, while also eliminating the pituitary tumor in a manner that allows for the eventual weaning of therapy.

\section{References}

1. Adjei AA, Hidalgo M: Intracellular signal transduction pathway proteins as targets for cancer therapy. J Clin Oncol 23:5386-5403, 2005

2. Aghi MK, Petit J, Chapman P, Loeffler J, Klibanski A, Biller $\mathrm{BM}$, et al: Management of recurrent and refractory Cushing's disease with reoperation and/or proton beam radiosurgery. Clin Neurosurg 55:141-144, 2008

3. Ahmed A, Furqan S, Islam N: Disappearance of pituitary macro adenoma with combination of ketoconazole and cabergoline treatment: an unusual case of Cushing's syndrome with interesting findings. BMJ Case Rep 2012: bcr0320126025, 2012

4. Ambrosi B, Bochicchio D, Fadin C, Colombo P, Faglia G: Failure of somatostatin and octreotide to acutely affect the hypothalamic-pituitary-adrenal function in patients with corticotropin hypersecretion. J Endocrinol Invest 13:257-261, 1990

5. Angeli A, Frairia R: Ketoconazole therapy in Cushing's disease. Lancet 1:821, 1985

6. Avgerinos PC, Yanovski JA, Oldfield EH, Nieman LK, Cutler 
GB Jr: The metyrapone and dexamethasone suppression tests for the differential diagnosis of the adrenocorticotropin-dependent Cushing syndrome: a comparison. Ann Intern Med 121:318-327, 1994

7. Barahona Constanzo MJ, del Pozo Picó C: New prospects for drug treatment in Cushing disease. Endocrinol Nutr 59:599-605, 2012

8. Batista DL, Zhang X, Gejman R, Ansell PJ, Zhou Y, Johnson SA, et al: The effects of SOM230 on cell proliferation and adrenocorticotropin secretion in human corticotroph pituitary adenomas. J Clin Endocrinol Metab 91:4482-4488, 2006

9. Baudry C, Coste J, Bou Khalil R, Silvera S, Guignat L, Guibourdenche J, et al: Efficiency and tolerance of mitotane in Cushing's disease in 76 patients from a single center. Eur J Endocrinol 167:473-481, 2012

10. Biller BM, Grossman AB, Stewart PM, Melmed S, Bertagna $\mathrm{X}$, Bertherat J, et al: Treatment of adrenocorticotropin-dependent Cushing's syndrome: a consensus statement. J Clin Endocrinol Metab 93:2454-2462, 2008

11. Boikos SA, Stratakis CA: Molecular genetics of the cAMPdependent protein kinase pathway and of sporadic pituitary tumorigenesis. Hum Mol Genet 16:R80-R87, 2007

12. Boscaro M, Ludlam WH, Atkinson B, Glusman JE, Petersenn S, Reincke M, et al: Treatment of pituitary-dependent Cushing's disease with the multireceptor ligand somatostatin analog pasireotide (SOM230): a multicenter, phase II trial. J Clin Endocrinol Metab 94:115-122, 2009

13. Broder MS, Neary MP, Chang E, Cherepanov D, Sun GH, Ludlam WH: Treatment patterns in Cushing's disease patients in two large United States nationwide databases: application of a novel, graphical methodology. Pituitary [epub ahead of print], 2014

14. Bruns C, Lewis I, Briner U, Meno-Tetang G, Weckbecker G: SOM230: a novel somatostatin peptidomimetic with broad somatotropin release inhibiting factor (SRIF) receptor binding and a unique antisecretory profile. Eur J Endocrinol 146:707-716, 2002

15. Castinetti F, Fassnacht M, Johanssen S, Terzolo M, Bouchard $\mathrm{P}$, Chanson P, et al: Merits and pitfalls of mifepristone in Cushing's syndrome. Eur J Endocrinol 160:1003-1010, 2009

16. Castinetti F, Morange I, Jaquet P, Conte-Devolx B, Brue T: Ketoconazole revisited: a preoperative or postoperative treatment in Cushing's disease. Eur J Endocrinol 158:91-99, 2008

17. Cavagnini F, Pecori Giraldi F: Epidemiology and follow-up of Cushing's disease. Ann Endocrinol (Paris) 62:168-172, 2001

18. Colao A, Petersenn S, Newell-Price J, Findling JW, Gu F, Maldonado M, et al: A 12-month phase 3 study of pasireotide in Cushing's disease. N Engl J Med 366:914-924, 2012

19. Dworakowska D, Grossman AB: The molecular pathogenesis of corticotroph tumours. Eur J Clin Invest 42:665-676, 2012

20. Engelhardt D, Weber MM: Therapy of Cushing's syndrome with steroid biosynthesis inhibitors. J Steroid Biochem Mol Biol 49:261-267, 1994

21. FDA approves mifepristone for patients with endogenous Cushing's syndrome. February 17, 2012. Healio. (http://www.healio.com/endocrinology/adrenal/news/ online/\%7Bb8a59db4-b59d-4d73-b07b-ebc0dd79f404\%7D/ fda-approves-mifepristone-for-patients-with-endogenouscushings-syndrome) [Accessed December 10, 2014]

22. Fleseriu M, Biller BM, Findling JW, Molitch ME, Schteingart DE, Gross C: Mifepristone, a glucocorticoid receptor antagonist, produces clinical and metabolic benefits in patients with Cushing's syndrome. J Clin Endocrinol Metab 97:2039-2049, 2012
23. Fukuoka H, Cooper O, Ben-Shlomo A, Mamelak A, Ren SG, Bruyette D, et al: EGFR as a therapeutic target for human, canine, and mouse ACTH-secreting pituitary adenomas. J Clin Invest 121:4712-4721, 2011

24. Gadelha MR, Vieira Neto L: Efficacy of medical treatment in Cushing's disease: a systematic review. Clin Endocrinol (Oxf) 80:1-12, 2014

25. Godbout A, Manavela M, Danilowicz K, Beauregard H, Bruno OD, Lacroix A: Cabergoline monotherapy in the long-term treatment of Cushing's disease. Eur J Endocrinol 163:709-716, 2010

26. Hameed N, Yedinak CG, Brzana J, Gultekin SH, Coppa ND, Dogan A, et al: Remission rate after transsphenoidal surgery in patients with pathologically confirmed Cushing's disease, the role of cortisol, ACTH assessment and immediate reoperation: a large single center experience. Pituitary 16:452-458, 2013

27. Hamrahian AH, Yuen KC, Hoffman AR: AACE/ACE Disease State clinical review: medical management of Cushing disease. Endocr Pract 20:746-757, 2014

28. Hofland LJ, Lamberts SW: The pathophysiological consequences of somatostatin receptor internalization and resistance. Endocr Rev 24:28-47, 2003

29. Iino K, Oki Y, Yamashita M, Matsushita F, Hayashi C, Yogo $\mathrm{K}$, et al: Possible relevance between prohormone convertase 2 expression and tumor growth in human adrenocorticotropinproducing pituitary adenoma. J Clin Endocrinol Metab 95:4003-4011, 2010

30. Karhu A, Aaltonen LA: Susceptibility to pituitary neoplasia related to MEN-1, CDKN1B and AIP mutations: an update. Hum Mol Genet 16:R73-R79, 2007

31. Labeur M, Paez-Pereda M, Arzt E, Stalla GK: Potential of retinoic acid derivatives for the treatment of corticotroph pituitary adenomas. Rev Endocr Metab Disord 10:103-109, 2009

32. Lehmann TP, Wrzesiński T, Jagodziński PP: The effect of mitotane on viability, steroidogenesis and gene expression in NCI-H295R adrenocortical cells. Mol Med Rep 7:893-900, 2013

33. Liu NA, Jiang H, Ben-Shlomo A, Wawrowsky K, Fan XM, Lin S, et al: Targeting zebrafish and murine pituitary corticotroph tumors with a cyclin-dependent kinase (CDK) inhibitor. Proc Natl Acad Sci U S A 108:8414-8419, 2011

34. Loose DS, Stover EP, Feldman D: Ketoconazole binds to glucocorticoid receptors and exhibits glucocorticoid antagonist activity in cultured cells. J Clin Invest 72:404-408, 1983

35. Melmed S: Pathogenesis of pituitary tumors. Nat Rev Endocrinol 7:257-266, 2011

36. Moher D, Liberati A, Tetzlaff J, Altman DG, PRISMA Group: Preferred reporting items for systematic reviews and meta-analyses: the PRISMA statement. J Clin Epidemiol 62:1006-1012, 2009

37. Molitch ME: Management of medically refractory prolactinoma. J Neurooncol 117:421-428, 2014

38. Moncet D, Morando DJ, Pitoia F, Katz SB, Rossi MA, Bruno OD: Ketoconazole therapy: an efficacious alternative to achieve eucortisolism in patients with Cushing's syndrome. Medicina (B Aires) 67:26-31, 2007

39. Neggers SJ, Franck SE, de Rooij FW, Dallenga AH, Poublon RM, Feelders RA, et al: Long-term efficacy and safety of pegvisomant in combination with long-acting somatostatin analogs in acromegaly. J Clin Endocrinol Metab 99:36443652,2014

40. Novartis drug Signifor ${ }^{\circledR}$ gains FDA approval as the first medication to treat Cushing's disease, a serious endocrine disorder. December 14, 2012. Novartis. (http://www.novartis. com/newsroom/media-releases/en/2012/1665290.shtml) [Accessed December 10, 2014]

41. Páez-Pereda M, Kovalovsky D, Hopfner U, Theodoropoulou 
M, Pagotto U, Uhl E, et al: Retinoic acid prevents experimental Cushing syndrome. J Clin Invest 108:1123-1131, 2001

42. Pardes E, De Yampey JE, Moses DF, De Nicola AF: Regulation of glucocorticoid receptors in human mononuclear cells: effects of glucocorticoid treatment, Cushing's disease and ketoconazole. J Steroid Biochem Mol Biol 39:233-238, 1991

43. Patil CG, Prevedello DM, Lad SP, Vance ML, Thorner MO, Katznelson L, et al: Late recurrences of Cushing's disease after initial successful transsphenoidal surgery. J Clin Endocrinol Metab 93:358-362, 2008

44. Pecori Giraldi F, Ambrogio AG, Andrioli M, Sanguin F, Karamouzis I, Corsello SM, et al: Potential role for retinoic acid in patients with Cushing's disease. J Clin Endocrinol Metab 97:3577-3583, 2012 (Errata in J Clin Endocrinol Metab 98:420 and J Clin Endocrinol Metab 98:1294)

45. Pivonello R, De Martino MC, Cappabianca P, De Leo M, Faggiano A, Lombardi G, et al: The medical treatment of Cushing's disease: effectiveness of chronic treatment with the dopamine agonist cabergoline in patients unsuccessfully treated by surgery. J Clin Endocrinol Metab 94:223-230, 2009

46. Pivonello R, Petersenn S, Newell-Price J, Findling JW, Gu F, Maldonado M, et al: Pasireotide treatment significantly improves clinical signs and symptoms in patients with Cushing's disease: results from a Phase III study. Clin Endocrinol (Oxf) 81:408-417, 2014

47. Potts MB, Shah JK, Molinaro AM, Blevins LS, Tyrrell $\mathrm{JB}$, Kunwar S, et al: Cavernous and inferior petrosal sinus sampling and dynamic magnetic resonance imaging in the preoperative evaluation of Cushing's disease. J Neurooncol 116:593-600, 2014

48. Schmid HA, Schoeffter P: Functional activity of the multiligand analog SOM230 at human recombinant somatostatin receptor subtypes supports its usefulness in neuroendocrine tumors. Neuroendocrinology 80 (Suppl 1):47-50, 2004

49. Schteingart DE, Tsao HS, Taylor CI, McKenzie A, Victoria
R, Therrien BA: Sustained remission of Cushing's disease with mitotane and pituitary irradiation. Ann Intern Med 92:613-619, 1980

50. Sonino N, Zielezny M, Fava GA, Fallo F, Boscaro M: Risk factors and long-term outcome in pituitary-dependent Cushing's disease. J Clin Endocrinol Metab 81:2647-2652, 1996

51. Tani Y, Inoshita N, Sugiyama T, Kato M, Yamada S, Shichiri $\mathrm{M}$, et al: Upregulation of CDKN2A and suppression of cyclin D1 gene expressions in ACTH-secreting pituitary adenomas. Eur J Endocrinol 163:523-529, 2010

52. Tritos NA, Biller BM: Cushing's disease. Handb Clin Neurol 124:221-234, 2014

53. Uruno A, Saito-Hakoda A, Yokoyama A, Kogure N, Matsuda $\mathrm{K}$, Parvin R, et al: Retinoic acid receptor- $\alpha$ up-regulates proopiomelanocortin gene expression in AtT20 corticotroph cells. Endocr J 61:1105-1114, 2014

54. Verhelst JA, Trainer PJ, Howlett TA, Perry L, Rees LH, Grossman AB, et al: Short and long-term responses to metyrapone in the medical management of 91 patients with Cushing's syndrome. Clin Endocrinol (Oxf) 35:169-178, 1991

55. Wortsman J, Soler NG: Mitotane. Spironolactone antagonism in Cushing's syndrome. JAMA 238:2527, 1977

\section{Author Contributions}

Conception and design: Aghi, Lau. Acquisition of data: Lau, Rutledge. Analysis and interpretation of data: Aghi, Lau. Drafting the article: Lau, Rutledge. Critically revising the article: all authors. Reviewed submitted version of manuscript: all authors. Approved the final version of the manuscript on behalf of all authors: Aghi. Study supervision: Aghi.

\section{Correspondence}

Manish K. Aghi, Department of Neurological Surgery, University of California, San Francisco, 505 Parnassus Ave., Rm. M779, San Francisco, CA 94143-0112. email: aghim@neurosurg.ucsf.edu. 